\title{
Enhanced brain expression of genes related to cell proliferation and neural differentiation is associated with cortisol receptor expression in fishes
}

\author{
Sadoul Bastien ${ }^{1,}{ }^{*}$, Alfonso Sebastien ${ }^{1,2}$, Bessa E. ${ }^{3}$, Bouchareb A. ${ }^{4}$, Blondeau-Bidet E. ${ }^{5}$, Clair P. ${ }^{6}$, \\ Chatain Beatrice ${ }^{1}$, Bégout Marie-Laure ${ }^{2}$, Geffroy Benjamin ${ }^{1,{ }^{*}}$
}

${ }^{1}$ MARBEC, Univ Montpellier, CNRS, Ifremer, IRD, Palavas-Les-Flots, France

${ }^{2}$ Ifremer, Laboratoire Ressources Halieutiques de La Rochelle, Place Gaby Coll, L'Houmeau, France

${ }^{3}$ Graduate Program in Ecology, University of Brasília, Distrito Federal, Brazil

${ }^{4}$ Wellcome Trust Centre for Human Genetics, University of Oxford, Oxford, United Kingdom

${ }^{5}$ University of Montpellier, Ifremer, IRD, Centre National de la Recherche Scientifique, UMR MARBEC, Montpellier, France

${ }^{6}$ University of Montpellier, Montpellier GenomiX, Montpellier, France

* Corresponding authors : Bastien Sadoul, email address : bastien.sadoul@ifremer.fr ; Benjamin

Geffroy, email address : benjamin.geffroy@ifremer.fr

\begin{abstract}
:
Stress enhances or inhibits neurogenesis in mammals and some fish species. The link between the two processes is still unclear. Most studies have been performed in very specific stressful or altered environments. Despite the known inter-individual divergence in coping abilities within populations, the relationship between the stress axis and neurogenesis has never been addressed in unstressed individuals. Here we correlate brain expression of the pcna (proliferating cell nuclear antigen) and neurod1 (neurogenic differentiation factor 1) genes, two markers of neurogenesis, with transcripts of cortisol receptors in three fish species living in very distinct environments. Within the three species, individuals with the highest expression of neurogenesis genes were also those that expressed the high levels of cortisol receptors. Based on these correlations and the hypothesis that mRNA levels are proxies of protein levels, we hypothesize that within unstressed animals, individuals sensitive to cortisol perceive a similar environment to be more stimulating, leading to increased neurogenesis. Although it is difficult to determine whether it is sensitivity to cortisol that affects neurogenesis capacities or the opposite, the proposed pathway is a potentially fruitful avenue that warrants further mechanistic experiments.
\end{abstract}

Highlights

Neurogenesis and cortisol receptors genes positively correlate in brain of fishes. Three fish species from different environments show similar patterns. Unstressed animals were considered. 
Keywords : Neurogenesis, Stress, Glucocorticoid receptor, Mineralocorticoid receptor, Hypothalamopituitary-interrenal axis 
46 Coping with the environment is a major component of fitness traits, especially in

47 a world with increased environmental variability and frequent extreme events

48 (Bonier et al., 2009; Németh et al., 2013). The hypothalamo-pituitary-interrenal

49 axis plays a central role in coping abilities of fishes, with the final product, 
cortisol, acting as the endocrine activator of most physiological responses to

51 perturbations (Schreck and Tort, 2016). Most importantly, it allocates energy

52 initially directed towards the production of structures in the liver and muscles to

53 fuel coping behavior, osmoregulatory mechanisms, and immune responses

54 (Sadoul and Vijayan, 2016). Cortisol is also known to operate on the brain,

55 mostly by regulating its own production (Fryer and Peter, 1977) and its

56 transformation into the inactive metabolite, cortisone (Alderman and Vijayan,

57 2012), through a negative feedback loop. These effects occur primarily by the

58 binding of cortisol to its receptors, the glucocorticoid receptor (GR) and the

59 mineralocorticoid receptor (MR). These two receptors are found in many fish

60 tissues, including the brain (Faught et al., 2016).

61 Recent studies in fish have demonstrated that cortisol has a role in brain

62 physiology other than simply its own regulation. Cortisol treatment during

63 development was found to increase neurogenesis, affecting brain development,

64 in treated zebrafish, Danio rerio (Best et al., 2017). In contrast, a study in adult

65 rainbow trout, Oncorhynchus mykiss, demonstrated that elevated cortisol levels

66 lead to reduced cell proliferation in the brain (Sørensen et al., 2011). In addition,

67 inhibition of GR, reducing the actions of cortisol, was found to increase the 68 expression of genes related to neurogenesis during development (Nesan and 69 Vijayan, 2013). These studies highlight a link between the stress axis and 70 neurogenesis in fishes. However, the results are still inconsistent and the

71 mechanisms involved mostly unknown. It is still unclear whether such opposing

72 results are the consequence of differences between species or experimental set 73 up. 
74 Here, we investigated the relationship between the expression of genes related

75 to neurogenesis and those involved in cortisol signaling by exploring the natural 76 variability between individuals of three fish species from very distinct 77 environments: European sea bass, Dicentrarchus labrax, from temperate marine 78 waters, tetra fish, Odontostilbe pequira, from neotropical freshwater, and 79 rainbow trout, 0 . mykiss, from cold freshwater. Rainbow trout and European sea 80 bass are two major aquacultured species, well-described in the literature, 81 whereas 0 . pequira has only recently been used as a sentinel for the effect of 82 ecotourism in Brazil (Balduino et al., 2017; Geffroy et al., 2018). The expression 83 of PCNA and NeuroD1, generally considered to be the principal markers of cell 84 proliferation and neural differentiation, respectively (Sørensen et al., 2013), 85 were used in this study.

86

\section{Materials and Methods}

$88 \quad 2.1$ Study sites and sampling procedures

89 A) European sea bass (born the $17^{\text {th }}$ of October 2016) were reared at the 90 experimental station of Ifremer (Palavas-Les-Flots) for 10 months before being 91 sampled (10 ${ }^{\text {th }}$ of August 2017). All fish $(n=27)$ were euthanized using a lethal 92 dose of Ethyl-p-aminobenzoate (Benzocaine, E1501, Sigma, St Louis, MO, USA), 93 before being weighed ( $47 \mathrm{~g} \pm 15 \mathrm{~g}$ ). Then, the brain of each fish was immediately 94 extracted and placed in liquid nitrogen and stored at $-80^{\circ} \mathrm{C}$ prior to analysis.

95 B) Rainbow trout $(n=48)$ were sibs of fish used as part of another experiment 96 aiming to assess the effects of early stress on fish behavior at the juvenile stage 97 (Poisson et al. 2017). Early maternal, artificial or pheromone stress was applied 

104 between groups for any investigated genes).

to juveniles (0-57 dpf). Fish were then reared at INRA (LPGP, Rennes) for seven months until sampling (11 ${ }^{\text {th }}$ of July 2016). All fish were euthanized using a lethal dose of 2-phenoxyethanol (1,000 ppm) and weighed (60 g $\pm 16 \mathrm{~g})$. The brain of each fish was then immediately extracted and placed in liquid nitrogen and stored at $-80^{\circ} \mathrm{C}$ prior to analysis. The early stress treatment did not affect gene expression at the group level at seven months (i.e. no significant differences

C) Tetra fish were collected as part of a previous study aiming to assess the impact of ecotourism on fish stress (Bessa et al., 2017). Fish (standard body

107 length: $2.5 \pm 0.5 \mathrm{~cm}$; weight: $0.22 \pm 0.1 \mathrm{~g}$ ), sampled from June to August 2014 in 108 both a touristic (total $n=15$ ) and control zone (without tourism, total $n=15$ ) in 109 the Cuiabazinho River Basin (Mato Grosso, Brazil), were flash frozen in liquid 110 nitrogen, after euthanasia, and stored at $-80^{\circ} \mathrm{C}$ in the laboratory of the Federal

111 University of Mato Grosso, Brazil, before being shipped to Rennes, France, for 112 gene expression measurements in the brain. The brain was placed in RNAlater ${ }^{\circledR}$ 113 solution for one day and stored at $-80^{\circ} \mathrm{C}$ prior to analysis. Fish from the touristic 114 zone displayed higher MR and neurod1 gene expression than fish from the non115 touristic zone, but we observed no interaction (i.e. fish with high levels of MR 116 were those with high levels of neurod1 in both populations).

$117 \quad 2.2$ Gene expression analysis

118 2.2.1 Extraction and reverse transcription of total RNA from the brain

119 For both European sea bass and rainbow trout, total RNA was extracted using Tri 120 Reagent (Molecular Research Centre, Cincinnati, OH), according to the 121 manufacturer's instructions. For tetra fish, total RNA was obtained following the 
instructions of the SV Total RNA isolation System kit (Promega®). RNA was

123 reverse transcribed using $200 \mathrm{U}$ Moloney murine leukemia virus (MMLV)

124 reverse transcriptase (Promega), $2 \mu \mathrm{g}$ random hexamers (Promega), and $25 \mathrm{U}$

125 RNase inhibitor (RNasin; Promega) in a final volume of $25 \mu$ l. The products were 126 then diluted 1:10 for quantitative real-time PCR (qPCR).

\section{2.2.2 Quantitative real-time PCR}

128 Primer sequences were retrieved from the literature (Backström et al., 2011;

129 Crespo et al., 2013; Pavlidis et al., 2011) or the primers were specially-designed 130 when the sequences were not available (Table 1 ). It was unknown whether $O$. 131 pequira possessed two isoforms of GR, similar to rainbow trout and sea bass, or 132 only one, such as for zebrafish. Based a phylogenetic analysis, the isoform 133 amplified for Tetra fish was within the GR2 cluster and therefore designated 134 GR2. QPCR was performed using the GoTaq® qPCR Master Mix (Promega) for 135 tetra fish and the SYBR Green PCR Master Mix (Applied Biosystems, Life 136 Technologies) for the other two species. The Step One Plus system (Applied 137 Biosystems, Foster City, CA) was used for all species. The hot start enzyme was 138 activated $2 \min$ at $95^{\circ} \mathrm{C}$ and amplification carried out using the following

139 program: $95^{\circ} \mathrm{C}$ for $3 \mathrm{~s}$ and $60^{\circ} \mathrm{C}$ (for rainbow trout and the European sea bass) or $14062^{\circ} \mathrm{C}$ (for tetra fish) for $30 \mathrm{~s}$ for 40 cycles. After amplification, a melting curve 141 was obtained using the following protocol: $10 \mathrm{~s}$ holding at $55^{\circ} \mathrm{C}$ followed by 142 sequential $0.05^{\circ} \mathrm{C}$ increases, repeated 80 times.

\section{$143 \quad$ 2.2.3 Housekeeping Genes}

144 Various housekeeping genes were used, depending on their intra-species 145 variation (assessed through the coefficient of variation: CV) and availability for 
146 the target species. Glyceraldehyde-3-phosphate dehydrogenase (gapdh), 147 ribosomal 18S (18S), ribosomal protein L13 (L13), eukaryotic translation 148 elongation factor 1 alpha (eef1-alpha), and $\beta$-Actin $(\beta$-Actin) are all 149 recommended reference genes for qPCR (Bland et al., 2012; Goidin et al., 2001; 150 Radonić et al., 2004). For European sea bass, L13 and eef1-alpha were used, with 151 CVs of 2.6 and 3.3\%, respectively. For rainbow trout, eef1-alpha and $\beta$-Actin were 152 used, with a common CV of $1.1 \%$. For tetra fish, gapdh and $18 S$ were used, with 153 CVs of $5.9 \%$ and $3.4 \%$, respectively. For all three species, the mean of the two 154 selected genes was used to calculate the relative quantity of each target gene.

2.3 Ethical statement

156 Experiments were authorized by ethics committee agreements C35-238-6 of 157 INRA-LPGP for rainbow trout, EEA\# 34-192-6 and APAFIS \#7098 for European 158 sea bass, and 2071343 of ICMBio (Brazilian biodiversity protection organ) for 159 tetra fish. All procedures involving animals were in accordance with the ethical 160 standards of the institution and followed European Directive 2010/63 UE.

1612.4 Statistical analyses

162 Statistical analyses were performed using R 3.1.0 software (R core team, 2014). 163 All statistical analyses were carried out at a 95\% level of significance. Two 164 samples of European sea bass and three of tetra fish were discarded due to RNA 165 extraction failure, resulting in the analysis of a total of 26 European sea bass, 48 166 rainbow trout, and 27 tetra fish.

167 We first performed linear regression analysis between the expression of 168 neurogenesis genes (i.e., pcna and neurod1) and that of cortisol receptors (i.e., $169 m r, g r 1$, and $g r 2$ ) for each species. We also measured other genes to confirm that 
170 false correlations were not generated. We thus performed a linear regression

171 analysis between gene expression linked to neurogenesis (i.e., pcna and neurod1)

172 and that of genes not related to cortisol receptors (i.e., avt for European sea bass 173 and rainbow trout and $h s p 70$ for tetra fish).

\section{Results}

$176 \quad 3.1$ PCNA and cortisol receptors

177 The correlation by linear regression was significant between the expression of $178 p c n a$ and $m r$ for European sea bass, $\left(\mathrm{p}=0.02, \mathrm{~F}=6.15, \mathrm{R}^{2}=0.17\right)$, rainbow trout $179\left(\mathrm{p}<0.001, \mathrm{~F}=44.95, \mathrm{R}^{2}=0.48\right)$, and tetra fish $\left(\mathrm{p}=0.005, \mathrm{~F}=9.38, \mathrm{R}^{2}=0.24\right.$, 180 Figure 1.A). Similarly, the correlation between the expression of pcna and gr2 181 was also significant for European sea bass ( $\left.p=0.003, F=10.64, R^{2}=0.28\right)$, 182 rainbow trout $\left(\mathrm{p}<0.001, \mathrm{~F}=24.25, \mathrm{R}^{2}=0.33\right)$, and tetra fish $(\mathrm{p}<0.001, \mathrm{~F}=$ $18334.39, \mathrm{R}^{2}=0.56$, Figure 1.B) and for pcna and $g r 1$ for rainbow trout $(\mathrm{p}<0.001, \mathrm{~F}$ $184=30.76, R^{2}=0.39$; Figure 1.C), but not European sea bass $(p=0.76, F=0.01)$. 185 For $a v t$, the correlation with pcna was significant for rainbow trout $(\mathrm{p}=0.04, \mathrm{~F}=$ $\left.1864.38, \mathrm{R}^{2}=0.07\right)$, but not European sea bass $(\mathrm{p}=0.21, \mathrm{~F}=1.63) . h s p 70$ expression 187 did not correlate with that of pcna in tetra fish $(\mathrm{p}=0.69, \mathrm{~F}=0.16)$.

3.2 NeuroD1 and cortisol receptors

189 The correlation between the expression of neurod1 and $m r$ for European sea 190 bass was not significant $(\mathrm{p}=0.10, \mathrm{~F}=2.87)$, but it was significant for rainbow 191 trout $\left(\mathrm{p}<0.001, \mathrm{~F}=38.60, \mathrm{R}^{2}=0.44\right)$ and tetra fish $\left(\mathrm{p}<0.001, \mathrm{~F}=77.43, \mathrm{R}^{2}=\right.$ 192 0.75, Figure 2.A). The correlation between the expression of neurod1 and gr2 193 was not significant for European sea bass $(\mathrm{p}=0.25, \mathrm{~F}=1.41)$, but reached 
194 significance for rainbow trout $\left(\mathrm{p}<0.001, \mathrm{~F}=46.13, \mathrm{R}^{2}=0.49\right)$ and tetra fish $(\mathrm{p}<$ $1950.001, \mathrm{~F}=30.39, \mathrm{R}^{2}=0.53$; Figure 2.B) and for neurod1 and gr1 for rainbow 196 trout $\left(\mathrm{p}<0.001, \mathrm{~F}=19.28, \mathrm{R}^{2}=0.28\right.$; Figure $\left.2 . \mathrm{C}\right)$, but not European sea bass $(\mathrm{p}=$ $1970.93, \mathrm{~F}=0.01)$. Neither the expression of avt nor hsp70 significantly correlated 198 with that of neurod1 (European sea bass: $\mathrm{p}=0.12, \mathrm{~F}=2.58$; rainbow trout: $\mathrm{p}=0.22$, $199 \quad \mathrm{~F}=1.23$; tetra fish: $\mathrm{p}=0.61, \mathrm{~F}=0.27)$.

\section{Discussion}

202 This study shows, for the first time, that inter-individual variability in the 203 expression of brain cell proliferation and neural differentiation genes is 204 associated with the expression of cortisol receptors in three fish species. This 205 was observed in unstressed fishes randomly picked within a population. 206 Although we report only correlations, the strong effect highlighted here suggests 207 that individuals with higher expression of cortisol receptor transcripts display 208 stronger neurogenesis in a non-stressful environment.

209 Although molecular mechanisms of MR on neurogenesis are still poorly

210 understood, it is well-known GR directly influence the proliferation of neural

211 stem cells through genomic and non-genomic mechanisms, as recently reviewed 212 in Odaka et al. (2017). Additionally, it was previously suggested that moderate 213 stress may stimulate neurogenesis in fish (Sørensen et al., 2013). This was

214 illustrated in one study on rainbow trout in which short confinement stress led 215 to increased expression of brain-derived neurotrophic factor (bdnf) and pcna in 216 the brain (Johansen et al., 2012). Similarly, enriched environments, associated 217 with small increases in cortisol levels (von Krogh et al., 2010), were described as 
stimulators of neurogenesis, shown by increased brain expression of neurod and

219 pcna (Salvanes et al., 2013; von Krogh et al., 2010). At the group level, the strain

220 of zebrafish with the highest baseline cortisol values also showed the strongest

221 levels of $m r$, gr-beta, pcna, and neurod transcripts, implying a similar relationship

222 (van den Bos et al., 2017). Social interactions were also found to increase

223 neurogenesis in the electric fish, Brachyhypopomus gauderio, which was

224 suggested to be mediated by GR (Dunlap et al., 2013). Comparable results were

225 obtained in mice placed in enriched environments or subjected to mild physical

226 activity, which both increased glucocorticoids levels, favoring neurogenesis

227 (Saaltink and Vreugdenhil, 2014). Thus, overall, low activation of glucocorticoid

228 receptors in the brain, through non-threatening stimuli or acute and rare

229 stressors, was shown to enhance neurogenesis in both mammals and fish. Here,

230 we speculate on another mode of action, independent of the environment,

231 linking the expression of GR and MR mRNA with neurogenesis. Although

232 previous results have demonstrated discrepancies between GR and MR

233 transcript levels, protein levels, and binding capacities, they were obtained

234 under artificial conditions that strongly affected plasma glucocorticoid levels,

235 such as exogenous cortisol administration (Sathiyaa and Vijayan, 2003; Vijayan

236 et al., 2003), or chemical adrenalectomy (Medina et al., 2013). In contrast, mRNA

237 and protein level of GR have been found to be highly consistent in unstressed

238 mammalian species throughout the brain (Herman and Spencer, 1998) or during

239 development (Owen and Matthews, 2003). We thus reasoned that GR and MR

240 mRNA levels are reasonable proxies for respective protein expression in

241 unstressed individuals, although this needs to be formally demonstrated.

242 Consequently, we propose that a same stressor can lead to various levels of 
neurogenesis due to variable levels of cortisol receptors in fishes. Whether this is

244 due to differences between individuals in their perception of the environment or

245 variability in their life history needs to be investigated further.

246 The strength of our data relies on the general pattern observed over three teleost 247 species living in very different environments and therefore sampled in three 248 highly separated regions. The observed common phenomenon suggests a 249 general teleost mechanism of interconnection between neurogenesis and 250 cortisol receptors. Such consistency among teleost species is not surprising, 251 given the strong evolutionary conservation of brain structures across fishes 252 (Ganz and Brand, 2016). By considering the whole brain, multiple regions with 253 specific functions and patterns of gene expression (Ganz and Brand, 2016) were 254 combined in this study. However, consistent effects of stress on cell proliferation 255 have been observed in different brain regions (Maruska et al., 2012), suggesting 256 that our results would be expected to be comparable for different brain regions.

257 Overall, our results further aid our understanding of how the environment can 258 dynamically drive cellular and molecular changes in the brain, with associated 259 ultimate consequences on experience-dependent behavior and fitness. We 260 therefore propose that inter-individual variability in cortisol receptors partially 261 explains differences in neurogenesis within a similar non-stressful environment.

\section{Acknowledgments}

264 We would like to thank Dr Patrick Prunet for providing the rainbow trout and for 265 his help during the sampling. Additionally, we thank Sébastien Szlabowicz for 266 performing the qPCR of the sea bass. 
269

270

271

272

273

274

275

276

277

278

279

280

281

282

283

284

285

286

287

288

289

290

291

292

293

294

295

296

297

298

299

300

301

302

303

304

305

306

307

308

309

310

311

312

313

Alderman, S.L., Vijayan, M.M., 2012. 11ß-Hydroxysteroid dehydrogenase type 2 in zebrafish brain: a functional role in hypothalamus-pituitary-interrenal axis regulation. J. Endocrinol. 215, 393-402.

https://doi.org/10.1530/JOE-12-0379

Backström, T., Schjolden, J., Øverli, Ø., Thörnqvist, P.-O., Winberg, S., 2011. Stress effects on AVT and CRF systems in two strains of rainbow trout (Oncorhynchus mykiss) divergent in stress responsiveness. Horm. Behav. 59, 180-186. https://doi.org/10.1016/j.yhbeh.2010.11.008

Balduino, G., Marques, T., Bessa, E., 2017. Fish assemblages from touristic and non-visited headwater streams differ. Environ. Biol. Fishes 100, 575-584. https://doi.org/10.1007/s10641-017-0586-1

Bessa, E., Geffroy, B., Gonçalves-De-Freitas, E., 2017. Tourism impact on stream fish measured with an ecological and a behavioural indicator. Aquat. Conserv. Mar. Freshw. Ecosyst. 27, 1281-1289.

Best, C., Kurrasch, D.M., Vijayan, M.M., 2017. Maternal cortisol stimulates neurogenesis and affects larval behaviour in zebrafish. Sci. Rep. 7, 40905. https://doi.org/10.1038/srep40905

Bland, F., McIntosh, R., Bain, N., Snow, M., 2012. Development and validation of a range of endogenous controls to support the implementation of practical Taqman real-time PCR-based surveillance for fish diseases within aquaculture. J. Fish Dis. 35, 447-454. https://doi.org/10.1111/j.13652761.2012.01363.x

Bonier, F., Martin, P.R., Moore,I.T., Wingfield, J.C., 2009. Do baseline glucocorticoids predict fitness? Trends Ecol. Evol. 24, 634-642. https://doi.org/10.1016/j.tree.2009.04.013

Crespo, B., Gómez, A., Mazón, M.J., Carrillo, M., Zanuy, S., 2013. Isolation and characterization of Ff1 and Gsdf family genes in European sea bass and identification of early gonadal markers of precocious puberty in males. Gen. Comp. Endocrinol. 191, 155-167. https://doi.org/10.1016/j.ygcen.2013.06.010

Dunlap, K.D., Chung, M., Castellano, J.F., 2013. Influence of long-term social interaction on chirping behavior, steroid levels and neurogenesis in weakly electric fish. J. Exp. Biol. 216, 2434-2441. https://doi.org/10.1242/jeb.082875

Faught, E., Aluru, N., Vijayan, M.M., 2016. 4 - The Molecular Stress Response, in: Schreck, C.B., Tort, L., Farrell, A.P., Brauner, C.J. (Eds.), Fish Physiology, Biology of Stress in Fish. Academic Press, pp. 113-166. https://doi.org/10.1016/B978-0-12-802728-8.00004-7

Fryer, J.N., Peter, R.E., 1977. Hypothalamic control of ACTH secretion in goldfish: III. Hypothalamic cortisol implant studies. Gen. Comp. Endocrinol. 33, 215-225. https://doi.org/10.1016/0016-6480(77)90246-5

Ganz, J., Brand, M., 2016. Adult Neurogenesis in Fish. Cold Spring Harb. Perspect. Biol. 8. https://doi.org/10.1101/cshperspect.a019018

Geffroy, B., Sadoul, B., Bouchareb, A., Prigent, S., Bourdineaud, J.-P., Gonzalez-Rey, M., Morais, R.N., Mela, M., Nobre Carvalho, L., Bessa, E., 2018. Nature- 
Based Tourism Elicits a Phenotypic Shift in the Coping Abilities of Fish. Front. Physiol. 9. https://doi.org/10.3389/fphys.2018.00013

Goidin, D., Mamessier, A., Staquet, M.-J., Schmitt, D., Berthier-Vergnes, O., 2001. Ribosomal 18S RNA Prevails over Glyceraldehyde-3-Phosphate Dehydrogenase and $\beta$-Actin Genes as Internal Standard for Quantitative Comparison of mRNA Levels in Invasive and Noninvasive Human Melanoma Cell Subpopulations. Anal. Biochem. 295, 17-21. https://doi.org/10.1006/abio.2001.5171

Herman, J.P., Spencer, R., 1998. Regulation of Hippocampal Glucocorticoid Receptor Gene Transcription and Protein Expression In Vivo. J. Neurosci. 18, 7462-7473. https://doi.org/10.1523/JNEUROSCI.18-18-07462.1998 Johansen, I.B., Sørensen, C., Sandvik, G.K., Nilsson, G.E., Höglund, E., Bakken, M., $\emptyset$ verli, Ø., 2012. Neural plasticity is affected by stress and heritable variation in stress coping style. Comp. Biochem. Physiol. Part D Genomics Proteomics 7, 161-171. https://doi.org/10.1016/j.cbd.2012.01.002

Maruska, K.P., Carpenter, R.E., Fernald, R.D., 2012. Characterization of cell proliferation throughout the brain of the African cichlid fish Astatotilapia burtoni and its regulation by social status. J. Comp. Neurol. 520, 34713491. https://doi.org/10.1002/cne.23100

Medina, C.O., Lattin, C.R., McVey, M., Romero, L.M., 2013. There is no correlation between glucocorticoid receptor mRNA expression and protein binding in the brains of house sparrows (Passer domesticus). Gen. Comp. Endocrinol. 193, 27-36. https://doi.org/10.1016/j.ygcen.2013.07.008

Németh, Z., Bonier, F., MacDougall-Shackleton, S.A., 2013. Coping with Uncertainty: Integrating Physiology, Behavior, and Evolutionary Ecology in a Changing World. Integr. Comp. Biol. 53, 960-964. https://doi.org/10.1093/icb/ict089

Nesan, D., Vijayan, M.M., 2013. The transcriptomics of glucocorticoid receptor signaling in developing zebrafish. PLoS ONE 8, e80726. https://doi.org/10.1371/journal.pone.0080726

Odaka, H., Adachi, N., Numakawa, T., 2017. Impact of glucocorticoid on neurogenesis. Neural Regen. Res. 12, 1028-1035. https://doi.org/10.4103/1673-5374.211174

Owen, D., Matthews, S.G., 2003. Glucocorticoids and Sex-Dependent Development of Brain Glucocorticoid and Mineralocorticoid Receptors. Endocrinology 144, 2775-2784. https://doi.org/10.1210/en.2002-0145

Pavlidis, M., Karantzali, E., Fanouraki, E., Barsakis, C., Kollias, S., Papandroulakis, N., 2011. Onset of the primary stress in European sea bass Dicentrarhus labrax, as indicated by whole body cortisol in relation to glucocorticoid receptor during early development. Aquaculture, Larvi 2009 315, 125130. https://doi.org/10.1016/j.aquaculture.2010.09.013

Radonić, A., Thulke, S., Mackay, I.M., Landt, O., Siegert, W., Nitsche, A., 2004. Guideline to reference gene selection for quantitative real-time PCR. Biochem. Biophys. Res. Commun. 313, 856-862.

Saaltink, D.-J., Vreugdenhil, E., 2014. Stress, glucocorticoid receptors, and adult neurogenesis: a balance between excitation and inhibition? Cell. Mol. Life Sci. 71, 2499-2515. https://doi.org/10.1007/s00018-014-1568-5 
Sadoul, B., Vijayan, M.M., 2016. 5 - Stress and Growth, in: Carl B. Schreck, L.T., Anthony P. Farrell and Colin J. Brauner (Ed.), Fish Physiology, Biology of Stress in FishFish Physiology. Academic Press, pp. 167-205.

Salvanes, A.G.V., Moberg, O., Ebbesson, L.O.E., Nilsen, T.O., Jensen, K.H., Braithwaite, V.A., 2013. Environmental enrichment promotes neural plasticity and cognitive ability in fish. Proc. R. Soc. B Biol. Sci. 280. https://doi.org/10.1098/rspb.2013.1331

Sathiyaa, R., Vijayan, M.M., 2003. Autoregulation of glucocorticoid receptor by cortisol in rainbow trout hepatocytes. Am. J. Physiol. Cell Physiol. 284, C1508-1515. https://doi.org/10.1152/ajpcell.00448.2002

Schreck, C.B., Tort, L., 2016. 1 - The Concept of Stress in Fish, in: Schreck, C.B., Tort, L., Farrell, A.P., Brauner, C.J. (Eds.), Fish Physiology, Biology of Stress in Fish. Academic Press, pp. 1-34. https://doi.org/10.1016/B978-0-12802728-8.00001-1

Sørensen, C., Bohlin, L.C., Øverli, Ø., Nilsson, G.E., 2011. Cortisol reduces cell proliferation in the telencephalon of rainbow trout (Oncorhynchus mykiss). Physiol. Behav. 102, 518-523. https://doi.org/10.1016/j.physbeh.2010.12.023

Sørensen, C., Johansen, I.B., Øverli, Ø., 2013. Neural plasticity and stress coping in teleost fishes. Gen. Comp. Endocrinol., Combined Special Issues: CESP 2012 and 7th AOSCE CongressThe International Symposium on Comparative Endocrinology and Stress Physiology (CESP) and the 7th Asia and Oceania Society for Comparative Endocrinology (AOSCE) Congress 181, 25-34. https://doi.org/10.1016/j.ygcen.2012.12.003 van den Bos, R., Mes, W., Galligani, P., Heil, A., Zethof, J., Flik, G., Gorissen, M., 2017. Further characterisation of differences between TL and $A B$ zebrafish (Danio rerio): Gene expression, physiology and behaviour at day 5 of the larval stage. PLOS ONE 12, e0175420. https://doi.org/10.1371/journal.pone.0175420

Vijayan, M.M., Raptis, S., Sathiyaa, R., 2003. Cortisol treatment affects glucocorticoid receptor and glucocorticoid-responsive genes in the liver of rainbow trout. Gen. Comp. Endocrinol. 132, 256-263. https://doi.org/10.1016/S0016-6480(03)00092-3

von Krogh, K., Sørensen, C., Nilsson, G.E., Øverli, Ø., 2010. Forebrain cell proliferation, behavior, and physiology of zebrafish, Danio rerio, kept in enriched or barren environments. Physiol. Behav. 101, 32-39. https://doi.org/10.1016/j.physbeh.2010.04.003 
Table 1. Primer sequences for gene expression analysis

\begin{tabular}{|c|c|c|c|c|}
\hline Species & Gene & $\begin{array}{c}\text { GenBank accession } \\
\text { numbers }\end{array}$ & Primers & Primer sequence \\
\hline \multirow{16}{*}{$\begin{array}{l}\text { Dicentrarchus } \\
\text { labrax }\end{array}$} & \multirow{2}{*}{$g r l$} & \multirow{2}{*}{$\mathrm{a}^{*}$} & gr1-F & 5'GAGATTTGGCAAGACCTTGACC3' \\
\hline & & & gr1-R & 5'ACCACACCAGGCGTACTGA3' \\
\hline & \multirow{2}{*}{$g r 2$} & \multirow{2}{*}{$a^{*}$} & gr2-F & 5'GACGCAGACCTCCACTACATTC3' \\
\hline & & & gr2-R & 5'GCCGTTCATACTCTCAACCAC3' \\
\hline & \multirow{2}{*}{$m r$} & \multirow{2}{*}{ JF824641.1 } & $\mathrm{mr}-\mathrm{F}$ & 5'GTTCCACAAAGAGCCCCAAG3' \\
\hline & & & mr-R & 5'AGGAGGACTGGTGGTTGATG3' \\
\hline & \multirow{2}{*}{ pcna } & \multirow{2}{*}{$b^{*}$} & pena-F & 5'CAGAGCGGCTGGTTGCA3' \\
\hline & & & pena-R & 5'CACCAAAGTGGAGCGAACAA3' \\
\hline & \multirow{2}{*}{ neurodl } & \multirow{2}{*}{$\mathrm{c}^{*}$} & neurod1-F & 5'TTCTCCTTCAGCGTGCACTA3' \\
\hline & & & neurod1-R & 5'GGTGCGAGTGTCCATCAAAG3' \\
\hline & \multirow{2}{*}{$\begin{array}{l}\text { eefl- } \\
\text { alpha }\end{array}$} & \multirow{2}{*}{ AJ866727.1 } & ef1-F & 5'AGATGGGCTTGTTCAAGGGA' \\
\hline & & & ef1-R & 5'TACAGTTCCAATACCGCCGA3' \\
\hline & \multirow{2}{*}{$L 13$} & \multirow{2}{*}{ DT044910.1 } & L13-F & 5'TCTGGAGGACTGTCAGGGGCATGC3' \\
\hline & & & $\overline{L 13-R}$ & 5'AGACGCACAATCTTGAGAGCAG3' \\
\hline & \multirow{2}{*}{$a v t$} & \multirow{2}{*}{$\mathrm{c}^{*}$} & avt-F & 5'CAATAGTTTTCTCCTCCAGTGCA3' \\
\hline & & & avt-R & 5'GGGGTGAGCAGGTAGTTCTC3' \\
\hline \multirow{16}{*}{$\begin{array}{c}\text { Oncorhynchus } \\
\text { mykiss }\end{array}$} & \multirow{2}{*}{$g r l$} & \multirow{2}{*}{ Z54210 } & gr1-F & 5'CCATCGTCAAGCGGGAAGAG3' \\
\hline & & & gr1-R & 5'GGAACTCCACGCTAAGGGATTTATTC3' \\
\hline & \multirow{2}{*}{$g r 2$} & \multirow{2}{*}{ AY495372 } & gr2-F & 5'CTCCGCTTTCTCCAGCAGCTA3' \\
\hline & & & gr2-R & 5'GTGAGCCACCCCGTAGTGACAG3' \\
\hline & \multirow[b]{2}{*}{$m r$} & & $\mathrm{mr}-\mathrm{F}$ & 5'GAAACAGATGATCCGCGTGGT3' \\
\hline & & AF209873 & $\mathrm{mr}-\mathrm{R}$ & 5'TGGATCAGGGTGATTTGGTCCT3' \\
\hline & & & pcna-F & 5'ATGTGGACAAGGAGGA3' \\
\hline & pcna & $d^{*}$ & pena-R & 5'CTATCTTGTACTCCACCA3' \\
\hline & & & neurod1-F & 5'TTAGGAGAAGTGCGGATA3' \\
\hline & $n$ & $e^{*}$ & neurod1-R & 5'GGCCCAAGTATTCGTTT3' \\
\hline & eef1 & & ef1-F & 5'AGGCATTGACAAGAGAACCATT3' \\
\hline & alpha & & ef1-R & 5'TGATACCACGCTCCCTCTC3' \\
\hline & & & Actine-F & 5'AGAGCTACGAGCTGCCTGAC3' \\
\hline & $\beta-A$ & AF1575 & Actine-R & 5'GCAAGACTCCATACCGAGGA3' \\
\hline & & & avt-F & 5'TGAACACACCCAGAATAGAGC3' \\
\hline & & $x^{*}$ & avt-R & 5'TCTACTTCTGCTGTGTGTCTG3' \\
\hline & & $\mathrm{KU}$ & gr-F & 5'GGAACACGCAGCACTATGTC3' \\
\hline & & KU820856 & gr-R & 5'CCTCCCGACTGTTTTCATGT3' \\
\hline & & KU820857 & $\mathrm{mr}-\mathrm{F}$ & 5'TGAGTCCATGGGCATCTACA3' \\
\hline & $m r$ & KU82085/ & $\mathrm{mr}-\mathrm{R}$ & 5’ATGGTGTTGGTGGAGCTTTC3' \\
\hline & $n c t$ & KL820860 & pena-F & 5'GACCTGATCACCGAGGCYTGCTGGG3' \\
\hline & pcna & KU8ZU860 & pena-R & 5'CTGTCGCAGCGGTAGGAGTCG3' \\
\hline Odontostilbe & & KUL20850 & neurod1-F & 5'AGATGCGGCGCATGAAGGCGAACGC3' \\
\hline & neurodI & KU820859 & neurod1-R & 5'CGGAGSGTCTCGATCTTGGAGAGCT3' \\
\hline & & & gapdh-F & 5'CAATGACCCCTTCATTGACC3' \\
\hline & gapdh & KU820855 & gapdh-R & 5'TAGTCAGCACCAGCATCACC3' \\
\hline & $18 \mathrm{~S}$ & KU820862 & $18 \mathrm{~S}-\mathrm{F}$ & 5'TCGCTAGTTGGCATCGTTTAT3' \\
\hline & $18 \mathrm{~S}$ & KU820862 & $18 \mathrm{~S}-\mathrm{R}$ & 5'CGGAGGTTCGAAGACGATCA3' \\
\hline & & & hsp70-F & 5'GACAACCAGCCCGGTGTCCTG3' \\
\hline & hsp70 & $\mathrm{g}^{*}$ & hsp70-R & 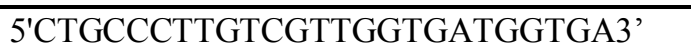 \\
\hline
\end{tabular}

$a^{*}$ from Pavlidis et al. 2011

b* from Crespo et al. 2013

$c^{*}$ designed from the available European seebass genome from UCSC

d* PREDICTED: Oncorhynchus mykiss proliferating cell nuclear antigen (LOC110525832), mRNA Sequence

ID: XM 021606282.1

e* PREDICTED: from Oncorhynchus mykiss neurogenic differentiation factor 1-like (LOC110520317), mRNA

Sequence ID: XM_021597549.1

$f^{*}$ from Backström et al (2011)

g* Based on the zebrafish gene: AF210640.1 - Efficiency:1.9; R-squared: 0.93 

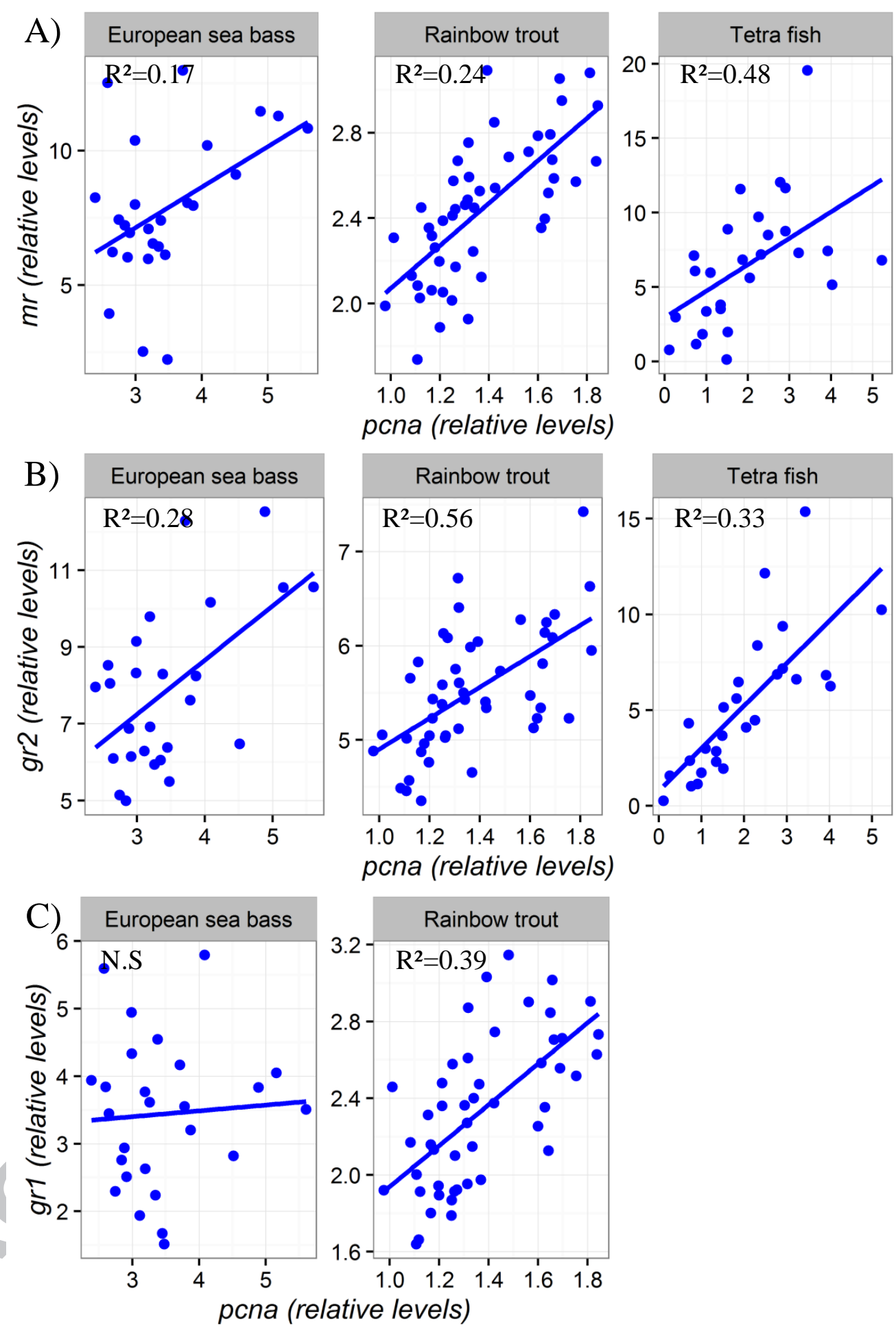

Figure 1. Gene expression of pcna in European sea bass Dicentrarchus labrax (n = 26), rainbow trout Oncorhynchus mykiss $(\mathrm{n}=48)$, and tetra fish Odonstostilbe pequira ( $\mathrm{n}=27$ ) as a function of (A) $m r$; (B) $g r 2$, and (C) $g r 1$ gene expression. Gene expression was normalized against that of eef1-alpha and $I 13$ for European sea bass, $\beta$-Actin and eef1-alpha for rainbow trout, and gapdh and $18 \mathrm{~s}$ for tetra fish. $\mathrm{R}^{2}$ is indicated for each significant linear regression. Otherwise N.S (not significant) is indicated. 

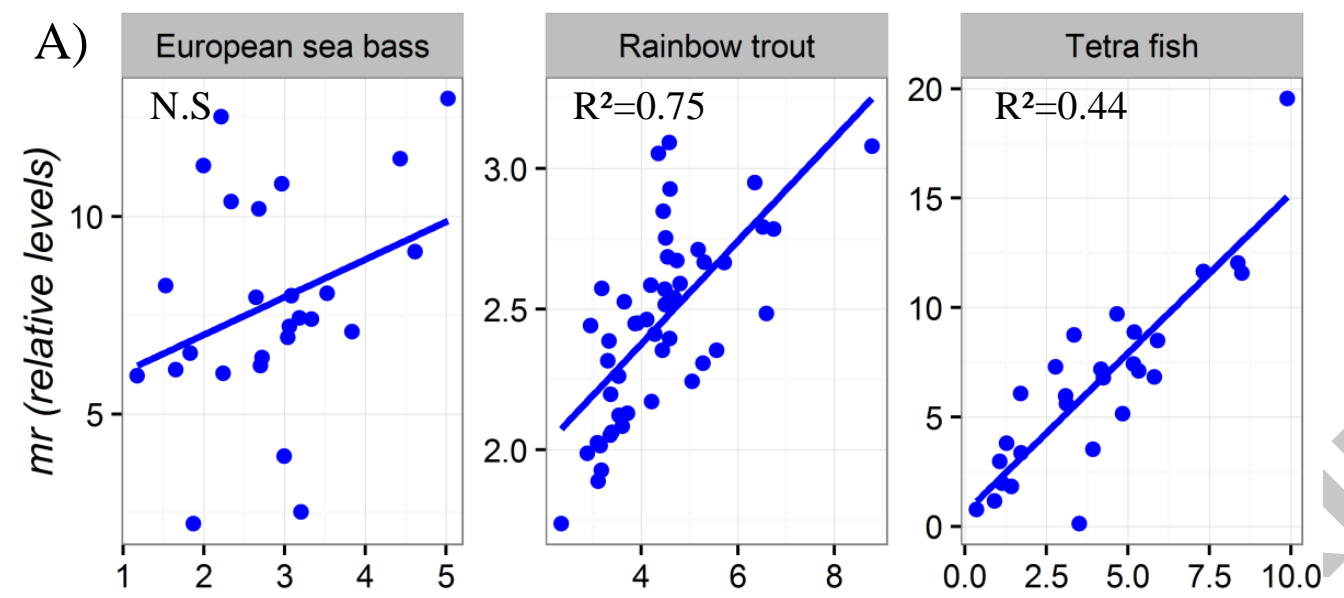

neurod1 (relative levels)
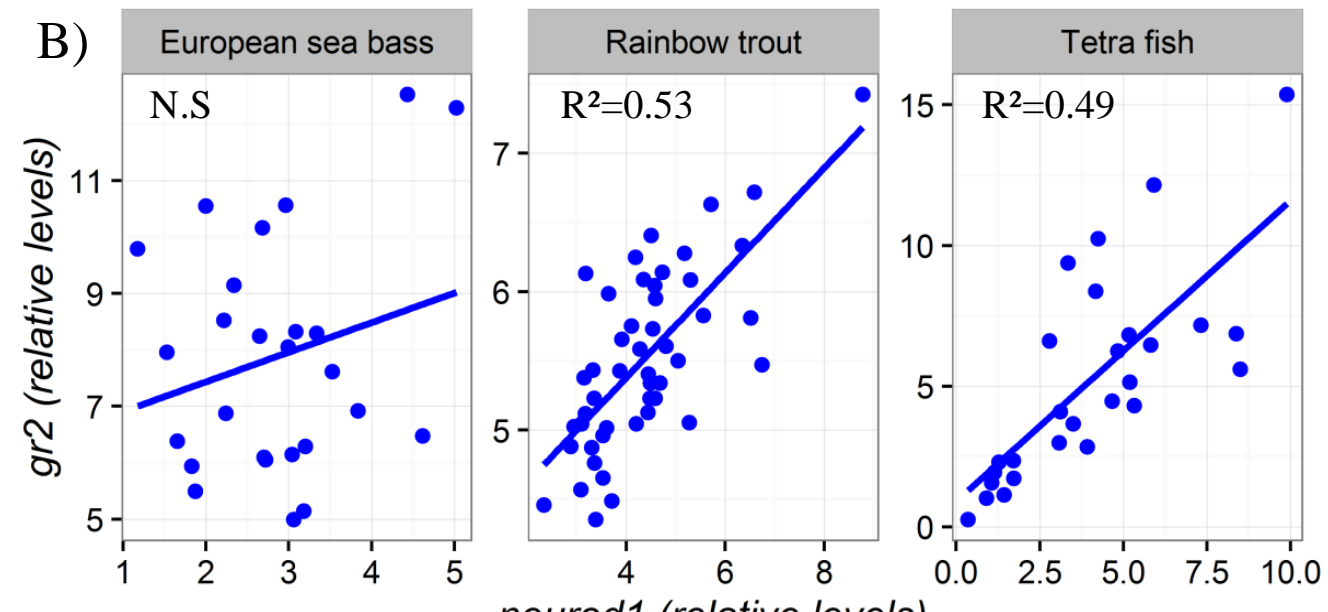

neurod1 (relative levels)

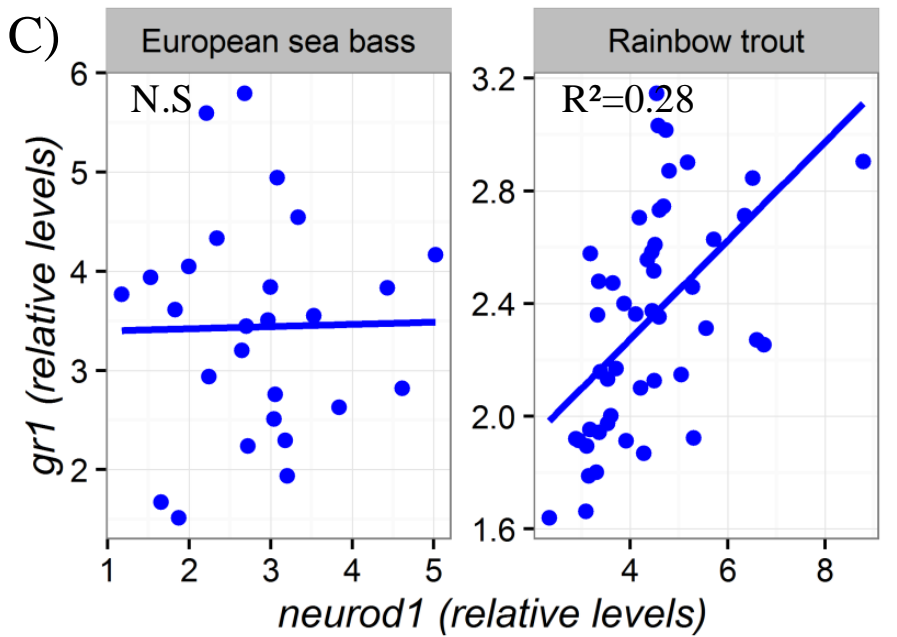

Figure 2. Gene expression of neurod1 in European sea bass Dicentrarchus labrax ( $\mathrm{n}=26)$, rainbow trout Oncorhynchus mykiss $(\mathrm{n}=48)$, and tetra fish Odonstostilbe pequira $(\mathrm{n}=27)$ as a function of (A) $m r,(\mathrm{~B}) \mathrm{gr2}$, and (C) gr1 gene expression. Gene expression was normalized against that of eef1-alpha and $l 13$ for European sea bass, $\beta$-Actin and eef1-alpha for rainbow trout, and gapdh and $18 s$ for tetra fish. $\mathrm{R}^{2}$ is indicated for each significant linear regression. Otherwise N.S (not significant) is indicated. 
Neurogenesis and cortisol receptors genes positively correlate in brain of fishes. Three fish species from different environments show similar patterns.

Unstressed animals were considered.

PCNA and neuroD are for the first time studied in O. Pecquira. 